THE JOURNAL OF THE LEARNING SCIENCES, 15(1), 11-34

Copyright (C) 2006, Lawrence Erlbaum Associates, Inc.

\title{
Complex Systems in Education: Scientific and Educational Importance and Implications for the Learning Sciences
}

\author{
Michael J. Jacobson \\ Learning Sciences Laboratory \\ National Institute of Education \\ Nanyang Technological University, Singapore \\ Uri Wilensky \\ Departments of Learning Sciences and Computer Science \\ Center for Connected Learning and Computer-Based Modeling \\ Northwestern Institute on Complex Systems \\ Northwestern University
}

\begin{abstract}
The multidisciplinary study of complex systems in the physical and social sciences over the past quarter of a century has led to the articulation of important new conceptual perspectives and methodologies that are of value both to researchers in these fields as well as to professionals, policymakers, and citizens who must deal with challenging social and global problems in the 21 st century. The main goals of this article are to (a) argue for the importance of learning these ideas at the precollege and college levels; (b) discuss the significant challenges inherent in learning complex systems knowledge from the standpoint of learning sciences theory and research; (c) discuss the "learnability issue" of complex systems conceptual perspectives and review a body of literature that has been exploring how learning sciences pedagogical approaches can lead to student learning of important dimensions of complex systems knowledge; (d) argue that the cognitive and sociocultural factors related to learning complex systems knowledge are relevant and challenging areas for learning sciences research; and (e) consider ways that concepts and methodologies from the study of complex systems raise important issues of theoretical and methodological centrality in the field of the learning sciences itself.
\end{abstract}

Correspondence should be addressed to Michael J. Jacobson, National Institute of Education, Nanyang Technological University, 1 Nanyang Walk, Singapore 637616. E-mail: jacobson@nie.edu.sg 
The study of complex systems - including both physical and social systems - is leading to the articulation of an integrated framework of ideas and methods that is generating excitement among scientists, policymakers, and segments of the public (Bar-Yam, 1997; Gell-Mann, 1994; Holland, 1995; Kauffman, 1993, 1995; Pagels, 1988; Prigogine \& Stengers, 1984; Waldrop, 1992; Watts \& Strogatz, 1998; Wolfram, 2002). Complex systems approaches, in conjunction with rapid advances in computational technologies, enable researchers to study aspects of the real world for which events and actions have multiple causes and consequences, and where order and structure coexist at many different scales of time, space, and organization. Within this complex systems framework, critical behaviors of systems that were systematically ignored or oversimplified by classical science can now be included as basic elements that account for many observed aspects of our world (Bar-Yam, 1997; Gell-Mann, 1994; Kauffman, 1995; Prigogine \& Stengers, 1984).

Complex systems theory is having considerable impact on the pure sciences. In addition, insights gained from the study of complex systems are being integrated into the working conceptual frameworks of many professions such as engineering, medicine, finance, law, and management. For example, the biological perspective of complex systems that highlights interdependence and co-evolution, with emergent patterns formed by self-organization, is now seen as equally important as the traditional perspective of competitive selection in understanding biological evolution (Kauffman, 1995). This perspective has also informed corporate managers' thinking about their employees and about their relationships with other corporations such as synergistic alliances versus competitive advantages (Axelrod \& Cohen, 1999; Brown \& Eisenhardt, 1998; Senge, 1990). Recently, this work has been extended to make use of a network-based perspective on organizational behavior (Gulati, 1998; Reagans \& Zuckerman, 2001; Uzzi, 1997; Watts \& Strogatz, 1998). There are many other examples from functional genomics and meteorological phenomena to the Internet and the global economy. Virtually all of these types of complex systems impact the everyday lives of individuals and the operation of organizations.

The conceptual basis of complex systems ideas reflects a dramatic change in perspective that is increasingly important for students to develop as it opens up new intellectual horizons, new explanatory frameworks, and new methodologies that are becoming of central importance in scientific and professional environments. Though some complex systems-related concepts are found in school curricula in the physical and social sciences, such as evolution by natural selection, equilibrium, and homeostasis, the overarching interdisciplinary or cross-domain nature of these concepts is not currently identified let alone exploited. Concepts and methodologies such as multiscale hierarchical organization, interdependence, emergent patterning, cellular automata, agent-based modeling, dynamical attractors, deterministic chaos, scale-free and small-world network topologies, information flows and constraints, system-environment interaction, developmental trajectories, fitness landscapes, 
and self-organization are becoming key conceptual tools for qualitative reasoning and quantitative modeling and simulation of real complex systems as well as synthetic or artificial systems (Bar-Yam, 1997; Pagels, 1988; Simon, 1999).

Unfortunately, little of the conceptual power embodied in the rapidly developing perspectives and tools of complex dynamical systems or informatics has informed the educational experience of our citizenry at any level, save that of graduate students in a few scientific areas. This absence from mainstream education creates many missed opportunities for building links between disparate elements of curriculum and providing unifying conceptual frameworks of coherence.

This article argues that the field of the learning sciences now has a major opportunity to help address the widening gap between current best understandings and analytical tools in the physical and social sciences (informed by complex systems) and the working knowledge of professionals, policymakers, and citizens who must deal with challenging social and global problems in the 21 st century. The learning sciences are well positioned to contribute in this area because many of the challenges learners of all ages face when trying to deeply understand ideas about complex systems are areas that have been the focus of research in the learning sciences for over a quarter of a century, such as conceptual change, knowledge transfer, representational forms, technological scaffolding and supports for enhanced learning, sociocultural dimensions of learning environments, and so on.

The five main goals of this article are to (a) argue for the importance of learning these ideas at the precollege and college levels; (b) discuss the significant challenges inherent in learning complex systems knowledge from the standpoint of learning sciences theory and research; (c) discuss the "learnability issue" of complex systems conceptual perspectives and review a body of literature that has been exploring how learning sciences pedagogical approaches can lead to student learning of important dimensions of complex systems knowledge; (d) argue that the cognitive and sociocultural factors related to learning complex systems knowledge are relevant and challenging areas for learning sciences research; and (e) consider ways that concepts and methodologies from the study of complex systems raise important issues of theoretical and methodological centrality in the field of the learning sciences itself.

\section{COMPLEX SYSTEMS AND LEARNING: A REVIEW OF THE LITERATURE}

The research to date on learning complex systems ideas and perspectives may be grouped into two main categories: cognitive challenges associated with understanding complex systems concepts and pedagogical research into learning com- 
plex systems perspectives. This section provides a review of the research in these two areas. ${ }^{1}$

\section{Complex Systems Concepts and Cognitive Challenges}

There is reason to believe that many of the core ideas associated with new ways of thinking about complex systems may be challenging for students to learn. Considerable research has documented a variety of difficulties students experience in learning concepts relevant to understanding complex systems that are currently taught in existing science courses. For example, many students-even at the college level-believe that chemical reactions stop at equilibrium (Kozma, Russell, Johnston, \& Dershimer, 1990; Stieff \& Wilensky, 2003) or that evolution is the result of trait use or disuse and that acquired traits are passed down from one generation to the next (Bishop \& Anderson, 1990; Samarapungavan \& Wiers, 1997). In addition, it has been suggested that important concepts related to complex systems may be counterintuitive or conflict with commonly held beliefs (Casti, 1994; Wilensky \& Resnick, 1999). Many people believe there is a linear relationship between the size of an action and its corresponding effect; that is, a small action has a small effect, whereas a large action has a correspondingly large effect (Casti, 1994). However, it is now commonly understood that, in complex and dynamical systems, a small action may have interactions in the system that contribute to a significant and large-scale influence-often metaphorically referred to as the so-called "butterfly effect" (Gleick, 1987; Lorenz, 1963).

Other researchers have proposed that people tend to favor explanations that assume central control and deterministic causality (Resnick \& Wilensky, 1993; Wilensky \& Resnick, 1995, 1999) and that people harbor deep-seated resistance toward ideas describing various phenomena in terms of self-organization, stochastic, and decentralized processes (Feltovich, Spiro, \& Coulson, 1989; Resnick, 1994, 1996; Wilensky, 1997a; Wilensky \& Resnick, 1999). Consistent with these perspectives, recent research suggests that not only do individuals with complex systems expertise have specialized conceptual understandings that novices do not have (as would be expected given their additional formal education), but also that complex systems novices and experts use different ontologies when constructing solutions to complex systems problems (Jacobson, 2000, 2001). Undergraduate students who were novices regarding their understanding of complex systems were found to solve complex systems problems using a set of "clockwork" ontological statements such as control of a system from a centralized source or action effects as being predictable. In contrast, complex systems experts solved these problems using a set of "complex systems" ontological statements in which sys-

${ }^{1}$ Note that the work of certain researchers contributes to both of these categories of complex systems and learning research. 
tem control emerged as part of decentralized interactions of elements or that described nonlinearities and randomness in action effects in a complex system.

More recent research by Hmelo-Silver and Pfeffer (2004) has also documented significant differences between how experts and novices think about complex systems. These researchers proposed a framework, Structures, Behaviors, and Functions (SBF), for describing complex systems that they used to examine children's and experts' representations of an aquatic system from the perspective of the parts or the structural elements of the system, the elements' behaviors or mechanisms, and the functional aspects of the system. Hmelo-Silver and Pfeffer found that children focused on the structures and provided little functional or mechanistic descriptions, whereas experts employed all three SBF components in their explanations.

Overall, these findings are consistent with research on expert and novice differences (Chi, Glaser, \& Farr, 1988; Larkin, McDermott, Simon, \& Simon, 1980; National Research Council, 2000) and with recent theories of conceptual change that propose cognitive structures such as ontological and epistemological beliefs or phenomenological primitives can strongly afford or constrain the ability of a learner to understand particular types of higher order concepts (Chi, 1992, 2005; diSessa, 1993; Vosniadou \& Brewer, 1992, 1994). Students learning to think in terms of complex systems ideas may need to go through a process of "strong" or "radical" conceptual change. Consequently, pedagogies and curricula for learning complex systems ideas will need to focus not only on the conceptual aspects of these ideas but also on enriching the cognitive network of beliefs and intuitions students have about the world and about knowledge so as to bridge to a complex systems perspective.

\section{Pedagogical Research Into Learning Complex Systems Ideas}

The research discussed in the previous section raises what might be called the learnability question: Can students at the precollege or even college level learn complex systems conceptual perspectives and ways of thinking about the world? Assuming students can learn at least core ideas about complex systems (with the understanding that this "core" of ideas currently remains to be articulated), a related question is, Does this require a paradigm shift in terms of how we think about learning, problem solving, and the development of curricula for what students will need to learn ${ }^{2}$ We believe preliminary answers to these fundamental questions are starting to emerge from research into learning complex systems ideas, which we review in this section.

There have been relatively few studies conducted regarding how students can learn complex systems concepts. Some of the earliest research projects to investi-

\footnotetext{
${ }^{2}$ We thank a reviewer for posing a variation of this question and challenging us to answer it.
} 
gate student learning of complex systems ideas were conducted by Resnick and Wilensky (Resnick \& Wilensky, 1993; Wilensky, 1996; Wilensky \& Resnick, 1995). These qualitative studies explored students' use of the StarLogo agent-based modeling program in thinking and learning about common examples of complex systems such as traffic jams and ants foraging for food. This work demonstrated that students were able to use the representational affordances of an agent-based modeling tool to support their reasoning and thinking about different types of complex systems. However, the students' new knowledge was often fragile and reverted to noncomplex systems ways of thinking when applying new ideas they had learned through the modeling examples to novel situations.

A body of research has accumulated evidence that certain complex systems ideas pose particular challenges for students to understand (Charles, 2002, 2003; Penner, 2000, 2001; Wilensky \& Resnick, 1999). A centrally important concept in complex systems research is emergence; that is, how local interactions of elements in a complex system at a microlevel can contribute to higher order macrolevel patterns that may have qualitatively different characteristics than the individual elements at the microlevel. However, research by Penner $(2000,2001)$ has documented that the concept of emergent patterning in complex systems is very difficult for students to learn from classroom and model-based learning activities. Even when micro- and macrolevel relationships are appreciated, students were found to ascribe causal primacy to the macrolevel of the system, which from a complex systems perspective is backward, because in general higher order properties emerge from the local interactions and not the reverse.

Wilensky and his colleagues at Northwestern's Center for Connected Learning and Computer-Based Modeling have conducted extensive research on students' learning about complex systems while engaged with multi-agent modeling and simulation environments such as NetLogo (Wilensky, 1999b). They have implemented their work in a wide variety of contexts and age levels with a particular focus on middle and high school students in urban schools exploring, modifying, and constructing NetLogo agent-based models. Case studies of ordinary students doing extraordinary projects in such environments have been conducted, such as middle and high school students deriving the ideal gas law from the microlevel interactions of gas particles in a box (Wilensky, 1999a, 2003; Wilensky, Hazzard, \& Froemke, 1999); creating and testing individual-level models of predator-prey interactions (Wilensky \& Reisman, 1998, in press); exploring the rates and directions of chemical reactions as derived from the behavioral "rules" for individual molecules (Kim, 2003; Stieff \& Wilensky, 2003); deriving properties of probability distributions from microlevel stochastic rules of elements (Abrahamson \& Wilensky, 2004; Wilensky, 1997a); exploring the emergent properties of materials from crystal elements (Blikstein \& Wilensky, 2004); modeling evolutionary processes (Centola, Wilensky, \& McKenzie, 2000); exploring the connections between individual preferences, social policy, urban land use, and housing patterns 
(Lechner, Watson, Wilensky, \& Felsen, 2003); and exploring the effects of school choice policy on achievement (Maroulis \& Wilensky, 2005a, 2005b).

These researchers have also documented difficulties students have in taking on an agent-based perspective and constructing emergent explanations of macrolevel phenomena, a set of difficulties that taken together they refer to as the "deterministic-centralized mindset" (Resnick \& Wilensky, 1993; Wilensky \& Resnick, 1999). One way to help students move beyond this mindset is to situate the discussion of complex phenomena in ordinary everyday contexts in which the students are not merely observers but actual participants (Levy \& Wilensky, 2004; Wilensky \& Stroup, 1999a). For example, "participatory simulations" may be used in which students in a classroom act out the roles of individual system elements and then to contrast and compare the results of the students' actions in the classroom system with the behavior of the complex everyday system (Abrahamson \& Wilensky, in press; Colella, Borovoy, \& Resnick, 1998; Resnick \& Wilensky, 1998; Wilensky \& Stroup, 1999a). To facilitate an innovative learning activity of this type, Wilensky and Stroup developed a simulation architecture, HubNet (1999b), to support participatory simulations. HubNet-based participatory simulations have been used to help students learn about a variety of complex systems, such as traffic patterns, molecular interactions, and the spread of epidemics (Wilensky \& Stroup, 2002). In analyzing student reasoning while engaged in participatory simulations and making sense of these different types of complex systems, it was found that students need two basic and complementing forms of reasoning: the "agent-based" form, in which students reason from the properties and behavior of individual system elements, and the "aggregate" form, in which students reason about the properties and rates of change of populations and other macrolevel structures (Berland \& Wilensky, 2005; Levy \& Wilensky, 2004; Wilensky \& Stroup, 2002).

Students' interactions with simulations of complex phenomena can reveal mistaken assumptions about these phenomena that can, potentially, foster opportunities for the students to articulate and modify their assumptions. Studying classroom discussions of students engaged in participatory simulations, Abrahamson and Wilensky (2005a, 2005b) characterize dimensions of complex phenomena that trigger incorrect agent-to-aggregate inferences. These dimensions include spatial-dynamic cues inherent in the simulations, such as the agents' velocity and density, as well as more conceptual or mental-simulation reasoning that interacts with the spatial-dynamic cues, such as (a) failing to anticipate emergence inherent in agents' rule-based interactions; (b) inappropriate proportional reasoning; (c) randomness-determinism confusions; and (d) ignoring the effect of feedback loops. Abrahamson and Wilensky concluded that "complex system heuristics" are difficult to develop because they often run counter to the "linear system heuristics" that appear to be more grounded in students' everyday experiences. They recommend that students work with simulations of complex systems so as to develop a 
repertory of cases that may then serve as analogs for reasoning about complex phenomena (see also Goldstone \& Wilensky, 2005).

Wilensky and Stroup (2004) have conjectured that a complement to "agent-based" and "aggregate" perspectives is needed for a robust understanding of complex systems. Among students participating in HubNet simulations, students were observed to rapidly alternate between bottom-up agent-based and top-down aggregate perspectives, which in turn gave the students greater explanatory power when discussing different types of complex systems. Wilensky, Hazzard, and Longenecker (2000) achieved promising results by explicitly teaching students the alternation strategy using what they called "emergent exercises."

In further research on student's understanding of agent and aggregate levels of complex systems, Levy and Wilensky (2004) interviewed sixth-grade students about everyday events in which there was a system for which both micro- and macrolevel explanations was possible. ${ }^{3}$ They found a pervasive strategy among the students that involved constructing a "mid-level," that is, a new level between the micro- and macrolevels. A mid-level, which typically was made up of small groups of individual elements of the system, appeared to reduce the amount of information needed to reason about the system. The cognitive construction of a mid-level thus helped students to form mental models of dynamic complex systems that were used in two main ways related to the students' more general understanding of complex systems principles. One way was bottom-up, in which small groups were formed as a result of local interactions. The bottom-up mid-level way of thinking was associated with a greater understanding of complex systems principles such as equilibration and stochasm. The second way that students formed mid-levels was top-down, in which the whole system was decomposed into smaller groups and those groups were treated as single entities. Unfortunately, the top-down mid-level approach was associated with a less robust understanding of complex systems.

In another program of research, two studies were conducted that investigated conceptual change and learning complex systems ideas (Charles, 2002, 2003). The first study was an experimental design that involved a 3-day workshop in which students (ages 16-18) in the experimental group heard class lectures on complex systems concepts, ran StarLogoT (Wilensky, 1997b) models of different types of complex systems, and had class discussions. Using a revised version of the complex systems analytical framework proposed by Jacobson (2001), students in the experimental group were found to employ an "emergent" explanatory framework to solve near and moderate transfer questions about complex systems phenomena, and to use significantly fewer "clockwork" framework explanations on near transfer questions than students in the control condition. The second study employed a qualitative case study design with nine students from the first study who were given cognitive coach-

\footnotetext{
${ }^{3}$ One such event in which extensive interviews were conducted involved students finding their spots when asked to do calisthenics in gym class.
} 
ing while working with a set of StarLogoT models of complex systems. The process-oriented data collected in the second study indicated that, although students showed learning gains related to four of the six concepts being taught about emergent causal processes, they had difficulty with understanding the concepts of "random actions" and "nonlinear effects" of agents in a complex system.

Though we are still at an early stage of research into learning about complex systems, overall, the studies discussed in this section suggest that students at pregraduate school levels, from approximately middle school through college, can learn and benefit from important concepts and perspectives related to the scientific study of complex systems. Given that one plausible view of the role of complex systems in education is that these ideas should only be taught at the graduate level because of their inherent difficulty, the "learnabilty" of complex system ideas by these younger students is an important general finding. Clearly certain ideas, such as nonlinearity, emergent properties, and stochastic processes, have been found to be challenging for students to learn. However, the application of diverse theory and research perspectives from the learning sciences is starting to shed light on factors that contribute to learning difficult ideas such as these. This work is developing innovative pedagogies and technologies that may help students develop a richer set of cognitive resources that scaffold and support their learning about complex systems ideas and methods. More generally, such research, by pushing the envelope of what kinds of advanced knowledge students can learn, promises to contribute to the learning sciences discussion of "what is hard" and "why is it hard."

\section{RESEARCH ON DESIGN PRINCIPLES FOR LEARNING THE SCIENCE OF COMPLEX SYSTEMS}

Thus far, we have sketched out a rationale for why students should learn emerging scientific perspectives related to the study of complex systems and discussed research on issues related to learning these ideas. We now propose a set of research issues related to general design principles for creating environments and tools to help students learn scientific ideas about complex physical and social systems. Whereas each of these design principles is explicitly informed by learning sciences theory and research and by a consideration of the successes and challenges identified in recent education and complex systems projects such as those discussed earlier, they also suggest a variety of new research issues that will need to be explored. In this section, we discuss five design principles that may yield promising learning sciences research: (a) experiencing complex systems phenomena; (b) making the complex systems conceptual framework explicit; (c) encouraging collaboration, discussion, and reflection; (d) constructing theories, models, and experiments; and (e) learning trajectories for deep understandings and explorations. In the section following, we elaborate on each of these principles and the research issues they provoke. 


\section{Experiencing Complex Systems Phenomena}

It is now widely accepted that, for students to learn science, they must build on their experiences and knowledge about the world (National Research Council, 2000). From these experiences, students construct beliefs about how things in the world behave, such as linear cause and effect (e.g., a small action has a small effect, whereas a large action has a large effect). However, as noted earlier, in a complex system, a small effect can be amplified and consequently contribute to a very large effect- the so-called "butterfly effect" (Gleick, 1987; Lorenz, 1963).

Thus students need opportunities to experience complex systems phenomena in ways that will let them enhance both their ontological and conceptual understandings. These phenomena might be commonly experienced in daily life, such as ants foraging for food or birds flocking, or they might exist along temporal or physical dimensions that challenge human sensory and cognitive capabilities, such as "the big bang" or the path of an electron. Of course, "non-everyday" or impossible-to-directly-experience phenomena have always presented special challenges for teachers to teach and for students to learn. But even "everyday" phenomena, seen through the conceptual and representational lenses of complex systems, may have important but not directly observable characteristics, such as the pheromone scent trails generated by ants when food is found. Thus, given appropriate conceptual and representational scaffolding in the learning environment, students should be able to tap into their everyday experiences and channel and enhance these experiences to construct understandings of complex systems that are cognitively robust.

In the past, students generally "experienced" scientific phenomena indirectly through textbooks and lectures using textual, linguistic, and pictorial representations to convey scientific perspectives about everyday and non-everyday phenomena, supplemented perhaps by direct experiences with experiments utilizing scientific instrumentation and techniques. Now, with the increasing power and decreasing cost of computational systems capable of visualizations and computational modeling, it is becoming possible for students and teachers to have access to new tools that are effectively identical to computational science tools scientists use to investigate complex systems. ${ }^{4}$ In this way, students now may have "direct virtual" experiences of complex systems phenomena through modeling systems of interest, generating data from these models, and importing data from real world or laboratory experiments into models.

Although it may be argued that computer simulations are inferior for educational purposes to physical experiences of scientific phenomena, we contend that contemporary ways of "doing science" increasingly involve both observations made with particular types of instrumentation as well as computational modeling

\footnotetext{
${ }^{4}$ Powerful agent-based modeling tools are now available specifically oriented for education, such as NETLOGO (http://ccl.northwestern.edu/netlogo) and STARLOGO (http://www.media.mit.edu/starlogo).
} 
and simulations of the systems being studied. Moreover, there are many complex phenomena for which classroom observations are impractical, unhelpful, or even impossible, such as phenomena that occur over very large or very small scales in time or in space. In addition, it is becoming increasingly difficult to distinguish observations from models and simulations. For example, physical observations often involve the use of computer-controlled sensors and analysis algorithms, while at the same time, computer models can take data from external devices monitoring the physical world (Blikstein \& Wilensky, 2004; Thornton, 1989; Tinker, 1996).

Given these changes in how practicing scientists now typically "do science," students at the precollege and undergraduate levels should have more opportunities to utilize new computational methodologies and tools to complement traditional scientific practices. There is thus a need for further research to investigate how students and teachers might best use complex systems informatics and representational tools as part of science inquiry projects involving complex systems phenomena as students learn relevant complex systems concepts and principles.

\section{Making the Complex Systems Conceptual Framework Explicit}

A second principle for designing learning environments and tools is to make the organizing conceptual framework explicit to the student (National Research Council, 2000). Thus research could investigate the learning efficacy of using core concepts related to complex systems as an explicit organizing and integrating conceptual framework for learning in the physical and social sciences (Jacobson, 2001). For example, all students have seen ants moving about, carrying pieces of food, and just generally "milling" around anthills. Yet despite this rather detailed real world observational experience of ants and, for high school and college students, biology class lessons related to social insects such as ants, a case may be made that few young children-let alone older children or even adults - have developed an understanding of important core complex systems concepts such as randomness in the movements by ants in the environment, positive feedback loops related to the generation of pheromone deposits when food is found, self-organization from decentralized interactions as an emergent characteristic of the ant trails to the colony, and so on (Jacobson, 2001). Research could explore how pedagogies and representational tools might be developed to help make an organized conceptual perspective based on complex systems ideas salient and explicit to learners and what the learning outcomes might be, such as depth of conceptual understanding and knowledge transfer.

\section{Encouraging Collaboration, Discussion, and Reflection}

Contemporary views of learning acknowledge important ways that knowledge and beliefs about the world are shaped and constructed in situated and socially mediated 
contexts (Brown, Collins, \& Duguid, 1989; National Research Council, 2000). Learning environments in which students come to experience and to construct their understandings about complex systems may be made significantly more powerful - not to mention more interesting, engaging, and motivating — by involving students with authentically interesting problems and projects that involve collaborative and cooperative interactions. For example, highly effective learning interactions may occur between peers or between peers and experts that involve real-time face-to-face or distributed synchronous or asynchronous computer-mediated communications (Koschmann, 1996; Pea, 1994; Scardamalia \& Bereiter, 1994).

The design of environments for learning about complex systems needs to take advantage of lessons learned from the extensive research on pedagogies that foster collaboration, discussion, and reflection (National Research Council, 2000). ${ }^{5}$ There is a need for studies of environments that involve collaborations and discussions in which students are provided metacognitive scaffolding and questions for reflection such as "What underlying mechanisms might give rise to the observed behavior?" "How sensitive is the outcome to changes in the model's parameters or assumed environment?" "How predictable is the behavior of this system and why?" This research could determine if collaborative interactions and the construction of shared artifacts and representations help students articulate or reify their ideas about complex systems, help them reflect on the possible limitations of their initial ideas and theories, or help them see how complex systems ideas might be plausible and useful for understanding particular systems of interest.

\section{Constructing Theories, Models, and Experiments}

A central tenet of constructivist and constructionist learning approaches is that a learner is actively constructing new understandings, rather than passively receiving and absorbing "facts." Consistent with this view, recent research has begun to explore different classroom techniques to help students learn important complex systems ideas, such as students generating questions, theories, and hypotheses about various phenomena and then running observational experiments and/or creating computational models related to their theories (Blikstein \& Wilensky, 2004; Klopfer \& Resnick, 2003; Stieff \& Wilensky, 2003; Wilensky \& Reisman, 1998; Wilensky \& Resnick, 1999). Further research is needed to explore the learning potential of students constructing and revising computational models with multi-agent or qualitative modeling software, and how model building activities may enhance student conduct of real world experiments related to the phenomena under consideration (Abrahamson \& Wilensky, 2005a, 2005b; Jackson, Krajcik, \&

\footnotetext{
${ }^{5}$ Some initial research in this area has been conducted by researchers of so-called CATAALYST technologies (Ares et al., 2004) and participatory simulation architectures (Abrahamson \& Wilensky, 2004; Colella et al., 1998; Wilensky \& Stroup, 1999).
} 
Soloway, 2000). Also, research could explore whether the explicit linking of model building (both conceptual models and computer models) and scientific experimentation about complex systems helps students come to understand that modern scientific inquiry is fundamentally grounded on cycles of theorizing, model building, and experimentation, which in turn iteratively lead to further theory and model revisions, and so on.

\section{Learning Trajectories for Deep Understandings and Explorations}

In this final principle for the design of tools and environments for learning about complex systems, research could investigate whether integrating complex systems knowledge and methodologies into the precollege and college curriculum does in fact foster trajectories of learning for students that lead to conceptual growth and deepening understandings over time, grade levels, and topics. For example, research could determine if complex systems concepts learned in one class (e.g., core concepts such as multiple agents, network topologies, feedback, self-organization, emergence) form a conceptual or representational toolkit (Levin, Stuve, \& Jacobson, 1999) that students use and enhance in subsequent classes. Research of this type could investigate if students realize that complex systems knowledge applies in many physical and social science areas, if they understand the relationship of general complex systems principles to domain-specific features of such systems (e.g., complex biological systems have similarities and differences to complex chemical or social systems), and if they exhibit far transfer by applying these understandings across subject areas that are traditionally regarded as distinct (e.g., use knowledge learned about complex chemical systems to solve problems in complex biological or social systems). Whereas empirical demonstrations of far transfer would be of great near-term importance to the learning sciences research community (see Goldstone \& Wilensky, 2005) with important long-term applied implications, it will also be important to explore the potential value of learning complex systems perspectives to enhance students' understanding of "traditional" content in the physical and social sciences (e.g., thermodynamics, evolution, homeostasis, feedback) as current content standards and assessments are based on these areas.

\section{COMPLEX SYSTEMS AND CURRICULAR FOCUS}

Many current science curricula have been criticized for superficially covering too many subjects, with the consequence that students typically fail to achieve a solid understanding of even a single domain (National Research Council, 1996, 2000). Consequently, it is vital that educational materials for complex systems not be de- 
veloped that are just an "add-on" to an already bloated and over-stretched science-and-mathematics curriculum. How might this be done?

There are many ways complex systems concepts could be infused into the curricular content of school subjects that could form the basis of a new type of scientific literacy (Jacobson, 2001). Across many domains, concepts derived from a complex systems analytical perspective have the potential to provide organization to the otherwise bewildering properties of diverse phenomena in the physical and social sciences. For example, complex systems concepts such self-organization and positive feedback may be seen to apply in biological systems such as insect colonies (Dorigo \& Stuetzle, 2004; Resnick, 1994) in social science systems such as economics (Anderson, Arrow, \& Pines, 1988; Epstein \& Axtell, 1996), and in engineering (Amaral \& Ottino, 2004; Ottino, 2004). As noted earlier, research is needed to explore if the use of appropriate pedagogies, curricular materials, and learning tools helps students understand that complex systems conceptual perspectives have relevance across what have traditionally been taught as separate subject areas in the natural sciences such as chemistry and biology as well as the social sciences such as psychology and economics. If so, then this would help to justify the need for curricular reforms at the college and precollege levels to obtain conceptual and curricular coherence and interconnectedness. In particular, cognitively powerful cross-domain links may be fostered by the design of modeling and simulation tools that scaffold structural and functional similarities between traditionally regarded distinct sets of physical and social science phenomena. For instance, at first glance, there is no reason to believe that a network capturing a cell's genetic network and a network capturing the topology of the World Wide Web would have much in common. It has been demonstrated, however, that many physical and social networks are similar in the sense that their degree distribution is scale-free (Barabasi \& Albert, 1999). This similarity is explained by an agent-level mechanism of growth and preferential attachment. Another area of research could explore whether a complex systems-infused curriculum allows both for depth of coverage of traditional physical and social science subjects and for cross-disciplinary conceptual and cognitive "hooks" that may support far transfer of knowledge to dramatically new situations and problems.

In addition, complex systems phenomena are well suited to problem- and inquiry-centered learning approaches that implement constructivist models of learning and teaching. Thus research could investigate whether a learner-centered curriculum that integrates complex systems perspectives helps address the unfortunate situation whereby many students view science as rote memorization of isolated and decontextualized facts for which they often see little use in their daily lives. Research could also explore if such a curricular approach helps make cross-disciplinary connections easier for teachers to teach and cognitively easier for students to appreciate and to learn, while also employing content in the physical and social sciences that is conceptually principled and current. 


\section{LEARNING ABOUT COMPLEX SYSTEMS: FURTHER QUESTIONS}

This article has advanced the argument that ideas and perspectives related to the study of complex systems are becoming important for students to learn at a wider and earlier range of grade levels than is currently the case. A secondary assertion is that research to date suggests that a wide range of students can understand and learn many of the core ideas related to the study of complex systems. However, clearly there are a number of learning, pedagogical, and curricular questions in this area that need further research. For example, which complex systems concepts and perspectives pose particular challenges for students to learn? Do students at different developmental or education levels have beliefs about the world that might constrain their understanding of complex systems ideas? Do students have particular trajectories of conceptual understanding over time to learn knowledge such as this? Will longitudinal studies document deeper and more connected understandings of "traditional" science concepts (e.g., evolution, homeostasis) by students who study complex systems phenomena and ideas? What types of conceptual, metacognitive, and representational scaffolding might students need to learn complex systems ideas, particularly in the context of inquiry and project-centered learning activities? How might technological tools be designed and used to support teaching and learning of complex systems knowledge? Are there issues related to the appropriateness of particular complex systems concepts for various age and development levels? What are the critical teaching issues related to integrating complex systems perspectives into the classroom? How might teachers-including school teachers and university faculty in teacher education units in colleges and schools of education-learn complex systems ideas and pedagogical approaches? What are the issues that would need to be faced to integrate complex systems ideas more widely into the K-16 curriculum? Research-based investigations of these and other questions will be vital to inform future efforts that seek to shorten the 20to 30-year gap that often exists between the articulation of new scientific knowledge and the integration of these ideas into mainstream education, as well as to advance our understanding in the learning sciences for how to foster learning of challenging and important knowledge in other subject areas.

In closing this section, it is still an open research question to determine if complex systems perspectives represent radically new ways of thinking that pose uniquely difficult challenges for learners. If so, a related open question is whether the field of the learning sciences has the conceptual and methodological toolkits to conduct principled research that spans multiple areas including cognitive and developmental, classroom, and school learning environments, curriculum and assessment, and so on. It may be that to systematically investigate the learning of complex systems, researchers in the learning sciences would in fact be studying multilevel complex learning and educational systems. Ironically, learning scien- 
tists may need to adapt new complex systems conceptual perspectives and methodologies to study the students who would be learning selected complex systems ideas at a more basic level — an issue we consider further in the next section.

\section{IMPLICATIONS OF THE SCIENCES OF COMPLEX SYSTEMS FOR THE LEARNING SCIENCES}

There are important theoretical and methodological issues for the learning sciences that are raised by what might be called the complex systems framework of conceptual perspectives and principles. We use the term "framework" as it does not appear that there is a general "theory of complex systems" at this time. Rather, the multidisciplinary fields that study various types of complex systems use a set of conceptual perspectives or principles (e.g., multiscale hierarchical organization, emergent patterning, dynamical attractors, scale-free networks) and methods of doing science (e.g., computational modeling, network analysis) that function as a shared framework for the discourse and representations used in the conduct of scientific inquiry. As such, various fields can formulate specific theoretical perspectives of relevance to the study of particular complex systems of interest that still share common elements due to their grounding in the complex systems framework. The importance of this view of the potential value of complex systems for science relates to the Kauffman's (1995) observation that we may be at a historic juncture in which the relentless reductionism (i.e., increasingly fragmented and narrowly defined and isolated subspecialties) that has been occurring over the past three centuries of scientific disciplinary work may be coming to an end. ${ }^{6}$ However, historically, the field of the learning sciences (and its sister field, the cognitive sciences) has not been reductively fragmented, but rather has been grounded in multidisciplinary perspectives. Consequently, the question must be asked: From the point of view of learning science researchers, what do complex systems perspectives provide that are not already represented in the conceptual and methodological disciplinary toolkit of our field?

Our claim is that complex systems perspectives do provide new methods and insights for learning science research. As an example, we consider how complex systems perspectives may enhance or extend theory and research in the learning sciences through the use of computational modeling of systems of learning and education.

It has been argued that there has been a recent major shift in what constitutes legitimate sources of scientific information (Jackson, 1996). The origins of modern science are often credited to Aristotle and his use of careful observations to obtain information on which to make informed decisions rather than the logical argumentation

${ }^{6}$ For a discussion of a related perspective on recent developments in the history of science, see Goldstone (this issue). 
of philosophical beliefs. The next metamorphosis in the conduct of inquires we now regard as "science" occurred with the intellectual contributions of Brahe, Galileo, Newton, Kepler, Liebniz, and Euler, who not only advanced the field of mathematics, but who also demonstrated how new scientific discoveries could be made through the use of information derived from mathematical manipulations of observational data. The remarkable scientific achievements of the ensuing 300 years were predicated on these two sources of scientific information. Indeed, observational and mathematically derived information has been the norm in virtually all of the published research in the learning and cognitive sciences and in education to date.

However, Jackson (1996) has proposed that we are in the midst of a second historical metamorphosis in the conduct of science, one that involves the use of computational tools to generate a third legitimate source of scientific information. In addition to Jackson (1996), others, such as Pagels (1988), have observed how the use of computational tools in science allows dramatically enhanced capabilities to investigate complex and dynamical systems that otherwise could not be systematically investigated by scientists. These computational modeling approaches include cellular automata, network and agent-based modeling, neural networks, genetic algorithms, Monte Carlo simulations, and so on that are generally used in conjunction with scientific visualization techniques. Examples of complex systems that have been investigated with advanced computational modeling techniques include climate change (West \& Dowlatabadi, 1999), urban transportation models (Balmer, Nagel, \& Raney, 2004; Helbing \& Nagel, 2004; Noth, Borning, \& Waddell, 2000), and economics (Anderson et al., 1988; Arthur, Durlauf, \& Lane, 1997; Axelrod, 1997; Epstein \& Axtell, 1996). New communities of scientific practice have also emerged in which computational modeling techniques, in particular agent-based models and genetic algorithms, are being used to create synthetic worlds such as artificial life (Langton, 1989, 1995) and artificial societies (Epstein \& Axtell, 1996) that allow tremendous flexibility to explore theoretical and research questions in the physical, biological, and social sciences that would be difficult or impossible in "real" or nonsynthetic settings.

The typical approach used by researchers involved with computational science tools such as agent-based modeling is to articulate a model of the system of interest in terms of hypothesized rules that define the interactions between agents and between agents and their environment. In scientific computational modeling work, as opposed to explorations of modeling by mathematicians, there generally is an existing body of observational and mathematical information about the system that allows (a) an initial specification of the parameters for the model and (b) a validity check of the articulated model with the real world data, generally with iterative revisions to the model in terms of the parameters or rules the agents in a model follow in their interactions in the synthetic world. Once the researcher has demonstrated a valid model for a particular system compared to available data, it is then possible to run "computational experiments" in which what-if scenarios about the 
behavior of the system may be explored to understand a system under different conditions than the observed data and to perhaps envision different possible futures for how the system might behave over time. It is important to understand, however, that nearly all examples of complex systems have important random or chaotic (i.e., sensitivity to initial conditions) factors that mean there is a high probability that each run of the model may be different, sometimes in small ways but perhaps in dramatically large and chaotic ways (i.e., the "butterfly effect").

Given the development of sophisticated computational modeling tools and their increasing acceptance in a wide range of scientific fields in the physical and social sciences, we argue that there is great potential to accept computationally generated information as part of research in the learning and cognitive sciences that explores complex learning, sociocognitive, and educational systems. We believe that such work has enormous potential in four broad ways. First, the articulation of models, particularly those that are "bottom-up" such as agent-based models, often helps researchers distill their qualitative intuitions about critical factors that might be most responsible for the behavior of the system of interest. This "analytical catalyst" function of computational model building is often quite valuable when confronting systems of multidimensional and multilevel complexity. Second, complex systems models then become scientifically inspectable artifacts that, as mentioned earlier, may be compared to real world data and iteratively revised to improve the fit of the model. Third, models validated with one or more datasets may be used to explore the behavior of the system by varying model parameters (ideally with multiple runs involving all parameter combinations to investigate stochastic properties of the system). Fourth, such models may function as a tool to help generalize the findings from the observed and modeled system(s) to similar types of systems that probably have different specific local features.

In learning sciences related research to date, there have been but a couple of examples of computational modeling along the lines discussed in the previous paragraph. For example, Lemke and Sabelli (2004) have proposed building "SimSchool" or "SimDistrict" simulation programs that would not just model existing school or school district systems, but also could be used to create synthetic schools and district systems and to study their evolution over time in terms of needs, problems, and probable outcomes. Recently, a couple of actual systems have been developed along these lines. For example, researchers have done agent-based simulations for areas of educational policy such as school choice where parents and school officials are agents in the simulation (Lauen, 2004; Maroulis \& Wilensky, 2005a, 2005b). Researchers are also using network analysis methods to study topics ranging from how social structure impacts technology adoption in schools (Frank, Zhao, \& Borman, 2004) to the role of social structure on student achievement (Maroulis, Griesdorn, \& Gomez, 2005). Overall, there would seem to be great potential for computational modeling to enhance learning sciences research involving other types of micro- and macrolevels of cognitive, 
learning, and educational systems, such as the evolution of cognitive representational networks, design experiments of technology interventions in classrooms, and social network analysis of collaborative interactions patterns.

\section{CONCLUSION}

This article has provided an overview of issues, research, and reflections concerning the potential need for mainstream students to deeply learn about complex systems in the physical and social sciences. It will be important for perspectives from the sciences of learning to contribute to these inquires and explorations. In particular, researchers in the learning sciences may generate new scientific knowledge about the nature of learning related to current programs of interest in the field, such as conceptual change, knowledge transfer, and sociocultural dynamics of learning. If, as we hope, efforts are made over the next few years to evolve content standards in the physical and social sciences to infuse knowledge from emerging scientific understandings about complex systems into $\mathrm{K}-16$ curricula, these research findings will then lay the groundwork to inform the actual development of curricula and resources for learning about complex systems. Research exploring student learning of conceptually challenging knowledge such as complex systems ideas may push the envelope of what kinds of advanced knowledge students are capable of learning. In addition, at a research discipline "metalevel," conceptual perspectives and methodologies from complex systems have the potential to impact theory and research issues of central importance to the field of the learning sciences itself.

However, we are fully aware that we are just beginning the exploration of cognitive and learning issues associated with complex systems concepts and principles and of the theory and research implications that complex systems perspectives might have for the learning sciences. It remains to be determined how the study of complex systems might impact the field of the learning sciences and the enterprise of education more generally. We do well to heed Proust in saying that "The real voyage of discovery lies not in finding new landscapes, but in having new eyes."

\section{ACKNOWLEDGMENTS}

Portions of the work reported on in this article were supported, in part, by Grant REC-9980241 from the National Science Foundation (NSF) to the New England Complex Systems Institute (Yaneer Bar-Yam, principal investigator; Jim Kaput and Uri Wilensky, coprincipal investigators; organizing committee: Michael J. Jacobson, Eric Jakobsson, Jay Lemke, and Sheldon White). The article incorporates portions of the NSF final report and working papers (Kaput et al., 2001).

With due respect to the conventions of linearity in authorship lists, we regard the research reported in this article as an equal collaboration of both authors. The 
intellectual contributions of the scientists and researchers who participated in the working groups of the project and in follow-up meetings are gratefully acknowledged, although the responsibility for controversial issues or errors is that of the authors. The comments, suggestions, and insights of Robert L. Goldstone, Richard Lesh, and Dor Abrahamson on a previous version of this article and those of an anonymous reviewer are gratefully acknowledged.

\section{REFERENCES}

Abrahamson, D., \& Wilensky, U. (2004). S.A.M.P.L.E.R.: Statistics as multi-participant learning environment resource. Paper presented at the annual meeting of the American Educational Research Association, San Diego, CA.

Abrahamson, D., \& Wilensky, U. (2005a). Collaboration and equity in classroom activities using statistics as Multi-Participant Learning-Environment Resource (S.A.M.P.L.E.R.). Paper presented the annual meeting of the American Educational Research Association, Montreal, Canada.

Abrahamson, D., \& Wilensky, U. (2005b). The stratified learning zone: Examining collaborative-learning design in demographically-diverse mathematics classrooms. Paper presented at the annual meeting of the American Educational Research Association, Montreal, Canada.

Abrahamson, D., \& Wilensky, U. (in press). ProbLab: A computer-supported unit in probability and statistics. In M. J. Hoines \& A. B. Fuglestad (Eds.), Proceedings of the 28th Annual Meeting of the International Group for the Psychology of Mathematics Education. Bergen, Norway.

Amaral, L. A. N., \& Ottino, J. M. (2004). Complex networks: Augmenting the framework for the study of complex systems. European Physics Journal B, 38, 147-162.

Anderson, P. W., Arrow, K. J., \& Pines, D. (Eds.). (1988). The economy as an evolving complex system (Vol. 5). Redwood City, CA: Addison-Wesley.

Ares, N., Brady, C., Haertel, G., Hamilton, E., Kaput, J., Nasir, N., et al. (2004). Emerging RFT for a "Systems Learning Science." Paper presented at the SRI Cataalyst Workshop, Palo Alto, CA.

Arthur, B., Durlauf, S., \& Lane, D. (Eds.). (1997). The economy as an evolving complex system (Vol. II). Reading, MA: Addison-Wesley.

Axelrod, R. (1997). The complexity of cooperation: Agent-based models of competition and collaboration. Princeton, NJ: Princeton University Press.

Axelrod, R., \& Cohen, M. D. (1999). Harnessing complexity: Organizational implications of a scientific frontier. New York: Free Press.

Balmer, M., Nagel, K., \& Raney, B. (2004). Large-scale multi-agent simulations for transportation applications. Intelligent Transportation Systems, 8, 1-17.

Bar-Yam, Y. (1997). Dynamics of complex systems. Reading, MA: Addison-Wesley.

Barabasi, A. L., \& Albert, R. (1999). Emergence of scaling in random networks. Science, 286(5439), 509-512.

Berland, M., \& Wilensky, U. (2005). Complex play systems: Results from a classroom implementation of VBot. Paper presented at the annual meeting of the American Educational Research Association, Montreal, Canada.

Bishop, B. A., \& Anderson, C. W. (1990). Student conceptions of natural selection and its role in evolution. Journal of Research in Science Teaching, 27, 415-427.

Blikstein, P., \& Wilensky, U. (2004). MaterialSim: An agent-based simulation toolkit for Materials Science learning. Paper presented at the International Conference on Engineering Education, Orlando, FL.

Brown, J. S., Collins, A., \& Duguid, P. (1989). Situated cognition and the culture of learning. Educational Researcher, 18, 32-42.

Brown, S. L., \& Eisenhardt, K. M. (1998). Competing on the edge: Strategy as structured chaos. Boston, MA: Harvard Business School Press. 
Casti, J. L. (1994). Complexificantion: Explaining a paradoxical world through the science of surprise. New York: HarperCollins.

Centola, D., Wilensky, U., \& McKenzie, E. (2000). Survival of the groupiest: Facilitating students' understanding of the multiple levels of fitness through multi-agent modeling-The EACH Project. International Journal of Complex Systems.

Charles, E. S. (2002). Using complex systems thinking to facilitate shifts in ontological beliefs: A qualitative case study systematically investigating a learning and teaching context that employs "StarLogo" simulations and a one-on-one coaching methodology. Paper presented at the 83rd Annual Meeting of the American Educational Research Association, New Orleans, LA.

Charles, E. S. A. (2003). An ontological approach to conceptual change: The role that complex systems thinking may play in providing the explanatory framework needed for studying contemporary sciences. Unpublished doctoral dissertation, Concordia University, Montreal, Canada.

Chi, M. T. H. (1992). Conceptual change within and across ontological categories: Implications for learning and discovery in science. In R. Giere (Ed.), Minnesota studies in the philosophy of science: Cognitive models of science (Vol. XV, pp. 129-186). Minneapolis: University of Minnesota Press.

Chi, M. T. H. (2005). Commonsense conceptions of emergent processes: Why some misconceptions are robust. Journal of the Learning Sciences, 14, 161-199.

Chi, M. T. H., Glaser, R., \& Farr, M. J. (Eds.). (1988). The nature of expertise. Hillsdale, NJ: Lawrence Erlbaum Associates, Inc.

Colella, V., Borovoy, R., \& Resnick, M. (1998). Participatory simulations: Using computational objects to learn about dynamic. Paper presented at the Computer Human Interface (CHI) '98 Conference, Los Angeles, CA.

diSessa, A. (1993). Towards an epistemology of physics. Cognition and Instruction, 10, 105-225.

Dorigo, M., \& Stuetzle, T. (2004). Ant colony optimization. Cambridge, MA: MIT.

Epstein, J. M., \& Axtell, R. (1996). Growing artificial societies: Social science from the bottom up. Washington, DC: Brookings.

Feltovich, P. J., Spiro, R. J., \& Coulson, R. L. (1989). The nature of conceptual understanding in biomedicine: The deep structure of complex ideas and the development of misconceptions. In D. Evans \& V. Patel (Eds.), The cognitive sciences in medicine (pp. 113-172). Cambridge, MA: MIT.

Frank, K. A., Zhao, Y., \& Borman, K. (2004). Social capital and the diffusion of innovations within organizations: Application to the implementation of computer technology in schools. Sociology of Education, 77, 148-171.

Gell-Mann, M. (1994). The quark and the jaguar: Adventures in the simple and the complex. New York: Freeman and Company.

Gleick, J. (1987). Chaos: Making a new science. New York: Viking Penguin.

Goldstone, R. L. (this issue). The complex systems see-change in education. The Journal of the Learning Sciences.

Goldstone, R. L., \& Wilensky, U. (2005). Promoting transfer through complex systems principles. Manuscript submitted for publication.

Gulati, R. (1998). Alliances and networks. Strategic Management Journal, 19, 293-317.

Helbing, D., \& Nagel, K. (2004). The physics of traffic and regional development. Contemporary Physics, 45, 405-426.

Hmelo-Silver, C. E., \& Pfeffer, M. G. (2004). Comparing expert and novice understanding of a complex system from the perspective of structures, behaviors, and functions. Cognitive Science, 1, 127-138.

Holland, J. H. (1995). Hidden order: How adaptation builds complexity. New York: Addison-Wesley.

Jackson, E. A. (1996). The second metamorphosis of science: A second view (SFI Working Paper No. 96-05-059). Santa Fe Institute.

Jackson, S., Krajcik, J., \& Soloway, E. (2000). Model-It: A design retrospective. In M. J. Jacobson \& R. B. Kozma (Eds.), Innovations in science and mathematics education: Advanced designs for technologies of learning (pp. 77-115). Mahwah, NJ: Lawrence Erlbaum Associates, Inc. 
Jacobson, M. J. (2000). Butterflies, traffic jams, and cheetahs: Problem solving and complex systems. Paper presented at the annual meeting of the American Educational Research Association, New Orleans, LA.

Jacobson, M. J. (2001). Problem solving, cognition, and complex systems: Differences between experts and novices. Complexity, 6(3), 41-49.

Kaput, J., Bar-Yam, Y., Jacobson, M., Jakobsson, E., Lemke, J., \& Wilensky, U. (2001). Planning Documents for a National Initiative on Complex Systems in K-16 Education: Two Roles for Complex Systems in Education: Mainstream Content and Means for Understanding the Education System Itself. Final Report to the National Science Foundation on Project \#REC-9980241. Cambridge, MA: New England Complex Systems Institute. Retrieved from http://necsi.org/events/cxedk16/cxedk16.html.

Kauffman, S. (1993). The origins of order: Self-organization and selection in evolution. New York: Oxford University Press.

Kauffman, S. (1995). At home in the universe: The search for laws of self-organization and complexity. New York: Oxford University Press.

Kim, H. (2003). The use of modeling/simulation software in science education: An experiment with NetLogo software and the Connected Chemistry curriculum. Paper presented at the Twenty-First International Conference of the Korean Society for Educational Technology. Seoul, Korea.

Klopfer, E., \& Resnick, M. (2003). Technologies to support the creation of complex systems models: Using StarLogo software with students. Biosystems, 71, 111-123.

Koschmann, T. (1996). CSCL: Theory and practice on an emerging paradigm. Mahwah, NJ: Lawrence Erlbaum Associates, Inc. (CSCL is an abbreviation for Computer Supported Collaborative Learning)

Kozma, R., Russell, J., Johnston, J., \& Dershimer, C. (1990). College students 'understanding of chemical equilibrium. Paper presented at the Annual Meeting of the American Educational Research Association, Boston, MA.

Langton, C. (Ed.). (1989). Artificial life. Redwood City, CA: Addison-Wesley.

Langton, C. (Ed.). (1995). Artificial life: An overview. Cambridge, MA: MIT.

Larkin, J. H., McDermott, J., Simon, D. P., \& Simon, H. A. (1980). Expert and novice performance in solving physics problems. Science, 208, 1335-1342.

Lauen, D. (2004). An agent based modeling approach to school choice. Working Paper, University of Chicago.

Lechner, T., Watson, B., Wilensky, U., \& Felsen, M. (2003). Procedural modeling of land use in cities. Paper presented at the Midgraph Conference, Washington University, St. Louis, MO.

Lemke, J., \& Sabelli, N. (2004). Complex systems and educational change: Towards a new research agenda. Manuscript submitted for publication.

Levin, J. A., Stuve, M. J., \& Jacobson, M. J. (1999). Teachers' conceptions of the Internet and the World Wide Web: A representational toolkit as a model of expertise. Journal of Educational Computing Research, 21(1), 1-23.

Levy, S. T., \& Wilensky, U. (2004). Making sense of complexity: Patterns in forming causal connections between individual agent behaviors and aggregate group behaviors. Paper presented at the annual meeting of the American Educational Research Association, San Diego, CA.

Lorenz, E. N. (1963). Deterministic nonperiodic flow. Journal of Atmospheric Science, 20, 130-141.

Maroulis, S., Griesdorn, J., \& Gomez, L. (2005). Does "connectedness" matter? A social network analysis of small schools reform. Paper presented at the annual meeting of the American Educational Research Association, Montreal, Canada.

Maroulis, S., \& Wilensky, U. (2005a). Leave no turtle behind: An agent-based simulation of school choice dynamics. Paper presented at the annual meeting of the American Educational Research Association, Montreal, Canada.

Maroulis, S., \& Wilensky, U. (2005b). Modeling school districts as complex adaptive systems: A simulation of market-based reform. Paper presented at the 3rd Lake Arrowhead Conference on Human Complex Systems, Lake Arrowhead, California.

National Research Council. (1996). National Science Education Standards. Washington, DC: National Academy Press. 
National Research Council. (2000). How people learn: Brain, mind, experience, and school (Expanded Edition). J. D. Bransford, A. L. Brown, R. R. Cocking, \& S. Donovan (Eds.). Committee on Developments in the Science of Learning and Committee on Learning Research and Educational Practice. Washington, DC: National Academy Press.

Noth, M., Borning, A., \& Waddell, P. (2000). An extensible, modular architecture for simulating urban development, transportation, and environmental impacts (Technical Report No. 2000-12-01). Department of Computer Science and Engineering, University of Washington.

Ottino, J. M. (2004). Engineering complex systems. Nature, 427, 399.

Pagels, H. R. (1988). The dreams of reason: The computer and the rise of the sciences of complexity. New York: Simon \& Schuster.

Pea, R. D. (1994). Seeing what we build together: Distributed multimedia learning environments for transformative communications. Journal of the Learning Sciences, 3, 285-299.

Penner, D. E. (2000). Explaining systems: Investigating middle school students' understanding of emergent phenomena. Journal of Research in Science Teaching, 37, 784-806.

Penner, D. E. (2001). Complexity, emergence, and synthetic models in science education. In K. Crowley, C. D. Schunn, \& T. Okada (Eds.), Designing for science (pp. 177-208). Mahwah, NJ: Lawrence Erlbaum Associates, Inc.

Prigogine, I., \& Stengers, I. (1984). Order out of chaos: Man's new dialogue with nature. New York: Bantam Books.

Reagans, R., \& Zuckerman, E. W. (2001). Networks, diversity, and productivity: The social capital of corporate R\&D teams. Organization Science, 12, 502-517.

Resnick, M. (1994). Turtles, termites, and traffic jams: Explorations in massively parallel microworlds. Cambridge, MA: MIT.

Resnick, M. (1996). Beyond the centralized mindset. The Journal of the Learning Sciences, 5, $1-22$.

Resnick, M., \& Wilensky, U. (1993). Beyond the Deterministic, Centralized Mindsets: A New Thinking for New Science. Paper presented at the annual meeting of the American Educational Research Association, Atlanta, GA.

Resnick, M., \& Wilensky, U. (1998). Diving into complexity: Developing probabilistic decentralized thinking through role-playing activities. The Journal of the Learning Sciences, 7, 153-172.

Samarapungavan, A., \& Wiers, R. W. (1997). Children's thoughts on the origin of species: A study of explanatory coherence. Cognitive Science, 21, 147-177.

Scardamalia, M., \& Bereiter, C. (1994). Computer support for knowledge-building communities. The Journal of the Learning Sciences, 3, 265-283.

Senge, P. M. (1990). The fifth discipline: The art and practice of the learning organization. New York: Doubleday.

Simon, H. A. (1999). Can there be a science of complex systems? In Y. Bar-Yam (Ed.), Unifying themes in complex systems (pp. 3-14). Cambridge, MA: Perseus.

Stieff, M., \& Wilensky, U. (2003). Connected Chemistry: Incorporating interactive simulations into the chemistry classroom. Journal of Science Education and Technology, 12, 285-302.

Stroup, W., \& Wilensky, U. (2004). Embodied science learning: Students enacting complex dynamic phenomena with the HubNet architecture. Manuscript under review.

Thornton, R. (1989). Tools for scientific thinking: Microcomputer-based laboratories for physics teaching. Physics Education, 22, 230-238.

Tinker, R. (Ed.). (1996). Microcomputer based labs: Educational research and standards. Berlin: Springer-Verlag.

Uzzi, B. (1997). Social structure and competition in interfirm networks: The paradox of embeddedness. Administrative Science Quarterly, 42(1), 35-67.

Vosniadou, S., \& Brewer, W. F. (1992). Mental models of the earth: A study of conceptual change in childhood. Cognitive Psychology, 24, 535-585. 
Vosniadou, S., \& Brewer, W. F. (1994). Mental models of the day/night cycle. Cognitive Science, 18, $123-183$.

Waldrop, M. M. (1992). Complexity: The emerging science at the edge of order and chaos. New York: Simon \& Schuster.

Watts, D. J., \& Strogatz, S. (1998). Collective dynamics of "small world" networks. Nature, 393, $440-442$.

West, J. J., \& Dowlatabadi, H. (1999). On assessing the economic impacts of sea-level rise on developed coasts. In T. E. Downing, A. A. Olsthoorn, \& R. S. J. Tol (Eds.), Climate change and risk (pp. 205-220). New York: Routledge.

Wilensky, U. (1996). Modeling rugby: Kick first, generalize later? International Journal of Computers for Mathematical Learning, 1(1), 124-131.

Wilensky, U. (1997a). What is normal anyway? Therapy for epistemological anxiety. Educational Studies in Mathematics, 33(2), 171-202.

Wilensky, U. (1997b). StarLogoT [computer software]. Evanston, IL: Center for Connected Learning and Computer-Based Modeling, Northwestern University (http://ccl.northwestern.edu/cm/StarLogoT/).

Wilensky, U. (1999a). GasLab: An extensible modeling toolkit for exploring micro- and macro-views of gases. In N. Roberts, W. Feurzeig, \& B. Hunter (Eds.), Computer modeling and simulation in science education. Berlin: Springer-Verlag.

Wilensky, U. (1999b). NetLogo [computer software]. Evanston, IL: Center for Connected Learning and Computer-Based Modeling, Northwestern University (http://ccl.northwestern.edu/netlogo).

Wilensky, U. (2003). Statistical mechanics for secondary school: The GasLab Modeling Toolkit. International Journal of Computers for Mathematical Learning, 8(1), 1-41.

Wilensky, U., Hazzard, E., \& Froemke, R. (1999). An extensible modeling toolkit for exploring statistical mechanics. Paper presented at the Seventh European Logo Conference-EUROLOGO '99, Sofia, Bulgaria.

Wilensky, U., Hazzard, E., \& Longenecker, S. (2000). A bale of turtles: A case study of a middle school science class studying complexity using StarLogoT. Paper presented at a meeting of the Spencer Foundation, New York.

Wilensky, U., \& Reisman, K. (1998). Learning biology through constructing and testing computational theories: An embodied modeling approach. Paper presented at the Second International Conference on Complex Systems, Nashau, NH.

Wilensky, U., \& Reisman, K. (in press). Thinking like a wolf, a sheep or a firefly: Learning biology through constructing and testing computational theories - an embodied modeling approach. Cognition \& Instruction.

Wilensky, U., \& Resnick, M. (1995). New thinking for new sciences: Constructionist approaches for exploring complexity. Paper presented at the annual meeting of the American Educational Research Association, San Francisco, CA.

Wilensky, U., \& Resnick, M. (1999). Thinking in levels: A dynamic systems perspective to making sense of the world. Journal of Science Education and Technology, 8(1), 3-19.

Wilensky, U., \& Stroup, W. (1999a). Learning through participatory simulations: Network-based design for systems learning in classrooms. Paper presented at the Computer Supported Collaborative Learning Conference (CSCL '99), Palo Alto, CA.

Wilensky, U., \& Stroup, W. (1999b). HubNet [computer software]. Evanston, IL: Center for Connected Learning and Computer-Based Modeling, Northwestern University (http://ccl.northwestern.edu/ps).

Wilensky, U., \& Stroup, W. (2002). Participatory simulations: Envisioning the networked classroom as a way to support systems learning for all. Paper presented at the annual meeting of the American Research Education Association, New Orleans, LA.

Wolfram, S. (2002). A new kind of science. Champaign, IL: Wolfram Media. 